\title{
Penentuan Lokasi Makam Umum di Kota Kediri
}

\author{
M. Sayfuddin Anshori dan Sardjito \\ Departemen Perencanaan Wilayah dan Kota, Fakultas Arsitektur Desain dan Perencanaan, Institut \\ Teknologi Sepuluh Nopember (ITS) \\ e-mail: sardjito24@gmail.com
}

\begin{abstract}
Abstrak-Penggunaan lahan pada makam umum di Kota Kediri semakin meningkat. Sementara itu, luas makam umum di Kota Kediri tidak bertambah. Salah satu hal untuk mengatasinya adalah dengan mengembangkan makam umum. Untuk mencapai tujuan penelitian, penulis akan melakukan empat sasaran penelitian. Pertama menentukan faktor variabel penentu skor kesesuaian lahan makam umum. Adapun alat analisisnya yaitu menggunakan Analisis Analytical Hierarchy Process (AHP). Kedua, menentukan perkiraan kebutuhan lahan makam umum di Kota Kediri. Ketiga, menentukan alternatif lokasi makam umum berdasarkan skor kesesuaian lahan. Analisis pada sasaran ini menggunakan analisis kesesuaian lahan menggunakan GIS. Keempat, menentukan lokasi fasilitas makam umum yang ada di Kota Kediri. Analisisnya menggunakan analisis kesesuaian lahan berdasarkan ketentuan RTRW yang berlaku. Dari sejumlah lokasi alternatif, kemudian dipilih satu lokasi makam umum. Dari hasil analisis diketahui lokasi makam yang paling tepat. Yakni berada di timur Gunung Klotok dengan luas 60,84 hektar.
\end{abstract}

Kata Kunci_Kota Kediri, Makam Umum, Penetuan Lokasi.

\section{PENDAHULUAN}

$\mathrm{T}$ ERDAPAT tiga pemakaman umum milik Pemkot Kediri sebagaimana RTRW Kota Kediri. Yakni Makam Klotok, Setono Gedong, dan Semampir [1]. Luas Makam Klotok yakni $253.212 \mathrm{~m} 2$ dengan penggunaan 64 persen. Luas Makam Semampir yakni $12.346 \mathrm{~m} 2$ dengan penggunaan 90 persen. Adapun luas Makam Setono Gedong $4.426 \mathrm{~m} 2$ dengan penggunaan 85 persen.

Kesimpulannya, makam umum di Kota Kediri digunakan sebanyak 80 persen. Hanya 20 persen yang belum digunakan [1]. Selain itu, selama 10 tahun terakhir, tidak ada penambahan luas makam. Data menunjukkan bahwa dari 2006-2016, luas makam tetaplah $269.984 \mathrm{~m} 2$. Pada tahun 2021 diperkirakan makam umum eksisting akan habis terpakai.

Oleh karenanya, Pemerintah Kota Kediri berencana menambah makam umum baru. Yakni berada di tanah milik Kelurahan Campurejo dan Kelurahan Lirboyo. Rencananya kawasan tersebut juga menjadi wisata religi [2]. Mengingat wilayah seluas 50 ha tersebut berdekatan dengan Ponpes Lirboyo. Proses kajian telah dilakukan dan hanya tinggal studi kelayakan saja.

Namun, makam eksisting Ponpes Lirboyo kebanyakan diisi oleh kalangan kiai. Juga memiliki status sosial tinggi di masyarakat. Sehingga jika dipaksakan maka akan kurang memenuhi kebutuhan makam masyarakat. Masyarakat dan kerabat tidak akan terima jika makam kyai ditumpuk.
Dikhawatirkan, masalah pada tiga makam umum eksisting akan terulang kembali.

Terdapat hal-hal lain yang menghambat munculnya pemakaman baru. Di antaranya keengganan masyarakat untuk menjadikan makam di sekitar rumahnya. Hal tersebut dikarenakan kesan menakutkan dan mistis pada makam sendiri. Begitu juga ketidakmauan pengembang perumahan untuk membuat makam bagi penghuninya. Para pengembang khawatir jika perumahan yang dijual menjadi tidak laku.

\section{TINJAUAN PUSTAKA}

\section{A. Konsep Tempat Pemakaman Umum}

Pemakaman, menurut Kamus Besar Bahasa Indonesia (KBBI) adalah tempat mengubur. Pemakaman berfungsi untuk menguburkan orang meninggal, baik utuh maupun tidak. Keberadaan pemakaman umum sendiri telah dibuktikan sejak prasejarah [3]. Selama puluhan ribu tahun, pemakaman dijadikan tempat ritual [4]. Ritual yang dilakukan pun bergantung pada tradisi dan kepercayaan masing-masing.

\section{B. Konsep Penentuan Lokasi Makam}

Lokasi pemakaman sebaiknya tidak pada area yang mempunyai nilai tinggi. Termasuk pada area yang diprediksi akan menjadi tinggi nilai jualnya. Yaitu lahan dengan harga rendah atau sangat rendah [5]. Tujuannya untuk menghindari efek yang akan timbul dari keberadaan makam. Yakni penurunan nilai jual tanah tersebut dan sekitarnya.

Pemakaman sebaiknya berjarak minimal 50 meter dari jalan [5]. Tujuannya arus lalu lintas tidak saling terganggu oleh pengguna jalan. Hal tersebut juga dikaitkan dengan estetika keruangan dan kondisi jalan. Lokasi yang dipilih sebaiknya tidak terlalu dekat dengan area persawahan. Khususnya area persawahan yang memiliki nilai ekonomis yang begitu tinggi.

Jarak pemakaman dengan lokasi potensial minimal 500 meter [5]. Yakni lokasi yang berupa kegiatan perdaganganjasa, pemerintahan, perkantoran, dan sejenisnya. Keberadaan makam dapat menyebakan perembesan cairan racun ke area tersebut. Yakni racun yang berasal dari mayat yang telah lama membusuk. Akibatnya racun tersebut dapat mengganggu aktivitas-aktivitas penting masyarakat yang ada.

Adapun lokasi yang dipilih sebaiknya berupa RTH [1]. Sebagaimana dalam Rencana Tata Ruang Wilayah (RTRW) Kota yang berlaku. Bisa juga pada area lain yang didasarkan pada zoning text. Sehingga dapat mengurangi konflik penggunaan lahan yang terjadi di masyarakat. Menurut 
berbagai referensi, luas pemakaman minimal 10 hektar [5].

Tempat pemakaman sebaiknya tidak dibangun di area yang berpotensi longsor. Termasuk juga lokasi yang kemungkinan besar tidak menimbulkan pergerakan tanah. Sementara itu, lokasi yang dipilih adalah yang tingkat kemiringannya sedang. Yakni lokasi yang kemiringannya 2 sampai 15 persen [5]. Tujuannya agar tidak terjadi hal-hal seperti hilang atau rusaknya mayat.

Lokasi makam sebaiknya tidak berada pada daerah rawan bencana. Yakni pada area bebas banjir dan tanah longsor [5]. Termasuk yang memiliki kelerengan tidak curam dan baik kekuatan tanahnya. Hal tersebut tentu sangat menunjang pembangunan prasarana makam umum yang ada. Selain itu juga untuk mengurangi sejumlah hal yang tidak diinginkan.

Seiring berjalannya waktu, mayat semakin rusak dan membusuk [5]. Hal tersebut dapat menyebabkan polusi yang diakibatkan oleh pembusukan mayat. Polusi dapat berupa cairan, gas, dan padat, tergantung beberapa faktor. Mulai dari kondisi mayat sampai dengan keadaan lingkungan di sekitarnya. Akibatnya kawasan tersebut dan sekitarnya menjadi kurang baik kualitas lingkungannya.

Daerah serapan sangat memengaruhi manajemen air bersih di kawasan perkotaan. Karenanya area pemakaman sebaiknya terletak 300 meter dari area serapan. Lokasi pemakaman minimal 150 meter dari sumber air [5]. Hal tersebut untuk menghindari tercemarnya air sungai dari mayat busuk. Sehingga tidak membawa kerugian bagi manusianya maupun alam sekitar.

Sementara itu, lokasi pemakaman minimal terletak 500 meter dari pemukiman. Tempat pemakaman sebaiknya tidak pada daerah berpenduduk padat [5]. Hal tersebut dikarenakan banyaknya produksi polusi pada lokasi padat penduduk. Lokasi makam juga harus berada pada kedalaman air tanah tertentu. Yaitu kedalaman air tanah lebih dari 2,5 meter [6].

\section{Konsep Kebutuhan Prasarana Makam}

Karenanya, penentuan luas pemakaman sebaiknya mempertimbangkan aspek kependudukan [5]. Khususnya angka kematian yang menggambarkan kebutuhan makam yang paling akurat. Baik untuk beberapa tahun ke belakang maupun proyeksi masa mendatang. Sehingga dapat diketahui total kebutuhan luas lahan untuk pemakaman umum. Jika luas lahan tidak mencukupi maka dapat dilakukan penimbunan makam.

Sebuah makam dapat ditumpuk di atasnya setelah berumur 5 tahun. Hal tersebut mengacu pada Perwali 5/2016 Pasal 11 Ayat 4. Tentunya penumpukan tersebut harus disetujui oleh pemegang izin pengguna makam. Luas pemakaman seseorang maksimal 2,5 kali 1,5 meter (Ayat 1). Adapun jarak antara pemakaman satu dengan lainnya adalah 40 sentimeter.

Adapun luas pemakaman cina telah diatur dalam Perwali Nomor 9/2014. Panjang 3,5 meter lebar 1,7 meter (Pasal 4 Ayat 3). Dalam perwali tersebut juga disebutkan ketentuan prosesi pemakaman (Pasal 2). Yakni didasarkan agama dan kepercayaan masing-masing, termasuk tata letak jenazah. Mengingat masing-masing kepercayaan memiliki cara tersendiri mengenai perlakuan untuk jenazah.
Terdapat sejumlah fasilitas penunjang dalam sebuah makam umum [6]. Mulai dari jalan, parkir, pompa gedung, tempat kremasi, dan sebagainya. Dengan area yang dibutuhkan sekitar 35-50 \% dari luas makam. Tujuannya agar proses kegiatan pemakaman beserta sirkulasinya menjadi lebih lancar. Dari sini diketahui pula daya tampung pada suatu makam umum.

\section{Sintesa Tinjauan Pustaka}

Berdasarkan kajian pustaka sebelumnya, dapat disimpulkan mengenai penentu lokasi makam. Mulai dari aspek penggunaan lahan, fisik, sampai dengan aspek ekologi. Dari kajian pustaka, kemudian dapat disimpulkan indikator dan variabel penelitian. Dalam hal ini, indikator-variabel penelitian juga diintegrasikan dengan tujuan penelitian. Untuk lebih jelasnya, dapat dilihat pada tabel 1 penelitian ini.

\section{METODE PENELITIAN}

\section{A. Variabel Penelitian}

Variabel merupakan hal sesuatu yang akan diteliti yang memiliki ukuran. Sedangkan variabel penelitian merupakan variabel dasar yang dihasilkan dari sintesa. Yakni sintesa dari pengambilan tinjauan pustaka yang telah dilakukan sebelumnya. Variabel adalah suatu yang abstrak, namun menunjukkan objek-objek konkrit tertentu. Adapun macammacam variabel telah tercantum dalam Tabel 1 artikel ini.

Tabel 1.

\begin{tabular}{|c|c|c|c|}
\hline \multicolumn{4}{|c|}{ Variabel Penelitian } \\
\hline Indikator & Variabel & Definisi Operasional & $\begin{array}{l}\text { Kriteria } \\
\text { Kesesuaian } \\
\text { Lahan } \\
\end{array}$ \\
\hline \multirow[t]{3}{*}{$\begin{array}{l}\text { Aspek } \\
\text { Penggunaan } \\
\text { Lahan }\end{array}$} & Nilai Tanah & $\begin{array}{l}\text { Nilai tanah per meter } \\
\text { persegi }\end{array}$ & $\begin{array}{l}\text { Harga tanah } \\
\text { rendah atau } \\
\text { sangat rendah }\end{array}$ \\
\hline & $\begin{array}{l}\text { Pola Jaringan } \\
\text { Jalan }\end{array}$ & $\begin{array}{l}\text { Jarak antara jalan } \\
\text { umum atau rel kereta } \\
\text { api dengan dinding } \\
\text { makam }\end{array}$ & $\begin{array}{l}\text { Jarak } \\
\text { minimum } 50 \\
\text { meter }\end{array}$ \\
\hline & $\begin{array}{l}\text { Penggunaan } \\
\text { Lahan } \\
\text { Potensial } \\
\text { Penggunaan } \\
\text { lahan } \\
\text { eksisting }\end{array}$ & $\begin{array}{l}\text { Jarak antara batas area } \\
\text { potensial dengan } \\
\text { dinding makam } \\
\text { Penggunaan lahan } \\
\text { untuk kegiatan } \\
\text { tertentu berdasarkan } \\
\text { kondisi eksisting }\end{array}$ & $\begin{array}{l}\text { Jarak } \\
\text { minimum } 500 \\
\text { meter } \\
\text { Tanah } \\
\text { kosong, } \\
\text { rerumputan, } \\
\text { kebun }\end{array}$ \\
\hline \multirow[t]{3}{*}{ Aspek Fisik } & Topografi & $\begin{array}{l}\text { Tingkat kemiringan } \\
\text { lahan }\end{array}$ & $\begin{array}{l}2 \text { sampai } 15 \\
\text { persen }\end{array}$ \\
\hline & $\begin{array}{l}\text { Kondisi } \\
\text { Kebencanaan }\end{array}$ & $\begin{array}{l}\text { Intensitas terjadinya } \\
\text { bencana pada suatu } \\
\text { kawasan }\end{array}$ & $\begin{array}{l}\text { Tidak rawan } \\
\text { bencana } \\
\text { banjir, } \\
\text { kebakaran, } \\
\text { dan erosi }\end{array}$ \\
\hline & $\begin{array}{l}\text { Tingkat } \\
\text { Pergerakan } \\
\text { Tanah }\end{array}$ & $\begin{array}{l}\text { Intensitas pergerakan } \\
\text { tanah pada suatu } \\
\text { kawasan }\end{array}$ & $\begin{array}{l}\text { Pergerakan } \\
\text { tanah rendah }\end{array}$ \\
\hline \multirow[t]{2}{*}{$\begin{array}{l}\text { Aspek } \\
\text { Ekologi }\end{array}$} & $\begin{array}{l}\text { Kawasan } \\
\text { Permukiman }\end{array}$ & $\begin{array}{l}\text { Panjang antara batas } \\
\text { area permukiman } \\
\text { sebagaimana rencana } \\
\text { dengan dinding } \\
\text { makam }\end{array}$ & $\begin{array}{l}\text { Jarak } \\
\text { minimum } 300 \\
\text { meter }\end{array}$ \\
\hline & Hidrologi & $\begin{array}{l}\text { Panjang antara batas } \\
\text { sempadan sungai dan } \\
\text { danau dengan dinding } \\
\text { makam }\end{array}$ & $\begin{array}{l}\text { Jarak } \\
\text { minimum } 150 \\
\text { meter }\end{array}$ \\
\hline
\end{tabular}




\begin{tabular}{lll}
\hline Geologi & Jenis dan kondisi & Jenis tanah \\
& tanah yang ada di & aluvial, \\
& lokasi studi & latosol, \\
& & mediteran \\
\hline \hline
\end{tabular}

\section{B. Populasi dan Sampel Penelitian}

Adapun populasi penelitian ini adalah pemerintah dan masyarakat Kota Kediri. Teknik samplingnya menggunakan purposive sampling dan diolah menggunakan analisis AHP. Adapun sampel penelitian terdiri atas pemerintah dan masyarakat Kota Kediri. Pemilihan responden pihak pemerintah karena pemerintah berfungsi sebagai pemangku kebijakan. Sedangkan masyarakat merupakan pihak yang merasakan dampak langsung kebijakan pemerintah.

Dalam hal ini, pihak pemerintah terdiri atas beberapa instansi kelurahan. Termasuk dinas-dinas seperti Dinas PUPR, dan Dinas Perumahan-Permukiman Kota Kediri. Adapun pihak masyarakat berasal dari berbagai macam kalangan yang ada. Mulai dari pelajar, mahasiswa, PNS, pegawai swasta, wiraswasta, hingga pensiunan. Pihak masyarakat tersebar di berbagai penjuru kota dalam hal domisili.

Terdapat alasan yang melatarbelakangi penentuan jumlah responden sebanyak 100 orang. Yakni menjaga agar rasio konsistensi tidak melebihi 0,1 (10 persen). Tujuannya agar data yang didapatkan lebih dapat dipertanggungjawabkan dan valid. Adapun penghitungan jumlah sampel penelitiannya menggunakan rumus dari Slovin (1960). Jika penduduk Kota Kediri 281.978 jiwa (2016), maka jumlah sampelnya:

$$
\begin{aligned}
& n=\frac{N}{1+N \theta^{2}}=\frac{281,978}{1+281.978\left(0,1^{2}\right)}= \\
& 99,96 \text { atau dibulatkan menjadi } 100 \text { orang }
\end{aligned}
$$

Keterangan: $\mathrm{n}=$ jumlah sampel, $\mathrm{N}=$ jumlah populasi, $\mathrm{e}=$ margin error.

\section{HASIL DAN PEMBAHASAN}

\section{A. Menentukan Faktor dan Variabel Penentu Skor} Kesesuaian Lahan Makam Umum

Untuk mengetahui bobot skor kesesuaian lahan variabel sesungguhnya, dilakukanlah perhitungan. Yaitu dengan mengalikan priority vector variabel dengan priority vector indikator. Sehingga dapat digunakan dalam penentuan skor kesesuaian lahan makam umum. Adapun priority vector variabel dan indikator terdapat dalam subsubbab sebelumsebelumnya. Berikut merupakan bobot skor masing-masing variabel terhadap semua variabel penelitian.

\section{B. Menentukan Kebutuhan Lahan Makam Umum yang Ada di Kota Kediri}

Dalam menentukan lokasi makam umum, tentunya perlu dihitung terlebih dahulu. Seberapa besar lahan makam yang dibutuhkan oleh masyarakat Kota Kediri. Yang hendak dikuburkan di tempat pemakaman umum di Kota Kediri. Berikut kebutuhan luas makam berdasarkan jumlah kematian 5 tahun terakhir. Dihitung berdasarkan rumus sebagaimana ketentuan Perwali 5/2016 dan Neufert [6].

Tabel 3.

Kebutuhan Lahan Makam Umum di Kota Kediri

\begin{tabular}{ccccc}
\hline \hline Tahun & $\begin{array}{c}\text { TPU } \\
\text { Pojok }\end{array}$ & $\begin{array}{l}\text { TPU Setono } \\
\text { gedong }\end{array}$ & $\begin{array}{l}\text { TPU } \\
\text { Semampir }\end{array}$ & Total \\
\hline 2012 & 39 & 16 & 48 & 103 \\
2013 & 37 & 11 & 50 & 98 \\
2014 & 49 & 10 & 53 & 112 \\
2015 & 30 & 8 & 83 & 121 \\
2016 & 44 & 15 & 39 & 98 \\
Jumlah & 199 & 60 & 273 & 532 \\
Kebutuhan & $5,51 \mathrm{~m} 2 * 532$ jiwa $*(100 / 65)=4509,72 \mathrm{~m} 2$ per 5 tahun. \\
Lahan & & & & \\
Makam & & & & \\
\hline \hline
\end{tabular}

C. Menentukan Alternatif Lokasi Makam Umum Berdasarkan Hasil Skor Kesesuaian Lahan

Tabel 2.

\begin{tabular}{|c|c|c|}
\hline Indikator & Priority Vector Variabel & $\begin{array}{l}\text { Bobot Skor Variabel } \\
\text { Sesungguhnya }\end{array}$ \\
\hline Aspek & Nilai Tanah: 0,428 & $0,398 * 0,428=0,170$ \\
\hline Penggunaan & Pola Jaringan Jalan: 0,316 & $0,398 * 0,316=0,126$ \\
\hline \multirow[t]{2}{*}{ Lahan: 0,398} & $\begin{array}{l}\text { Penggunaan Lahan } \\
\text { Potensial: } 0,160\end{array}$ & $0,398 * 0,160=0,064$ \\
\hline & $\begin{array}{l}\text { Penggunaan lahan } \\
\text { eksisting: } 0,097\end{array}$ & $0,398 * 0,097=0,038$ \\
\hline Aspek Fisik: & Topografi: 0,418 & $0,426 * 0,418=0,178$ \\
\hline \multirow[t]{2}{*}{0,426} & $\begin{array}{l}\text { Kondisi Kebencanaan: } \\
0,365\end{array}$ & $0,426 * 0,365=0,156$ \\
\hline & $\begin{array}{l}\text { Tingkat Kekuatan Tanah: } \\
0,217\end{array}$ & $0,426 * 0,217=0,092$ \\
\hline $\begin{array}{l}\text { Aspek } \\
\text { Ekologi: }\end{array}$ & $\begin{array}{l}\text { Prasarana Permukiman: } \\
0,557\end{array}$ & $0,176 * 0,557=0,098$ \\
\hline \multirow[t]{2}{*}{$0,176^{\circ}$} & Hidrologi: 0,287 & $0,176 * 0,287=0,050$ \\
\hline & Geologi: 0,156 & $0,176 * 0,156=0,028$ \\
\hline
\end{tabular}

Bobot Skor Kesesuaian Lahan pada Masing-Masing Indikator dan Variabel

Setelah menganalisis kesesuaian lahan pada masing-masing variabel, dilakukanlah proses selanjutnya. Yaitu menentukan skor kesesuaian lahan pada masing-masing wilayah Kota Kediri. Berikut merupakan total luas area per masing-masing skor kesesuaian lahan. Yang dianalisis menggunakan teknik Weighted Overlay berdasarkan kriteria kesesuaian lahan. Yang selanjutnya menjadi dasar dalam penentuan lokasi makam umum baru.

Tabel 4.

Skor Kesesuaian Lahan Makam Umum di Kota Kediri Berdasarkan Luas

\begin{tabular}{lll}
\multicolumn{2}{c}{ Area } \\
\hline \hline Skor Kesesuaian & Total Luas & Persentase dari Total Luas \\
Lahan & Area (ha) & Wilayah Kota Kediri \\
\hline 1 & 0,20 & $0,00 \%$ \\
2 & 236,02 & $3,68 \%$ \\
3 & 2239,02 & $34,87 \%$ \\
4 & 3661,85 & $57,03 \%$ \\
5 & 283,98 & $4,42 \%$ \\
Jumlah & 6421,08 & $100,00 \%$ \\
\hline \hline
\end{tabular}

Selanjutnya dipilih sejumlah alternatif lokasi makam umum di Kota Kediri. Yakni area yang memiliki skor kesesuaian lahan 4 atau 5. Serta mempunyai luas minimal 10 hektar dengan penggunaan lahan tertentu. Antara lain lokasi yang berupa lahan kosong, rerumputan, dan kebun. Kemudian 
dipilihlah satu lokasi berdasarkan hasil analisis pada sasaran selanjutnya.

Tabel 5.

Alternatif Lokasi Makam Umum di Kota Kediri

\begin{tabular}{lll}
\hline \hline No. & Letak Lokasi Alternatif Makam & Luas Area (ha) \\
& Umum Baru Kota Kediri & \\
\hline 1 & Timur Area Wisata Gunung Klotok & 60,84 \\
2 & Utara Area Wisata Gunung Klotok & 14,59 \\
3 & Sepanjang Jalan Wisata Gunung & 12,31 \\
& Klotok & \\
\hline \hline
\end{tabular}

Pemerintah Kota Kediri telah memiliki rencana lokasi makam umum baru. Yakni di sekitar area Pondok Pesantren Lirboyo dengan sejumlah pertimbangan. Selain itu, hasil analisis di atas menunjukkan SKL Ponpes Lirboyo. Yakni 3 (agak jauh dari jalan) dan 4 (dekat jalan). Namun, berdasarkan analisis ini, Lirboyo tidak termasuk lokasi alternatif makam. Alasannya, karena penggunaan lahan eksisting Ponpes Lirboyo adalah sarana pendidikan/keagamaan.

Sementara alternatif lokasi yang dipilih adalah lahan kosong, rerumputan, kebun. Sehingga terjadi ketidaksesuaian antara kondisi eksisting dengan rencana dari pemkot. Lalu, terdapat alasan tidak adanya alternatif lokasi dengan skor 5 . Yakni karena tidak ada yang memenuhi luas minimal 10 hektar.

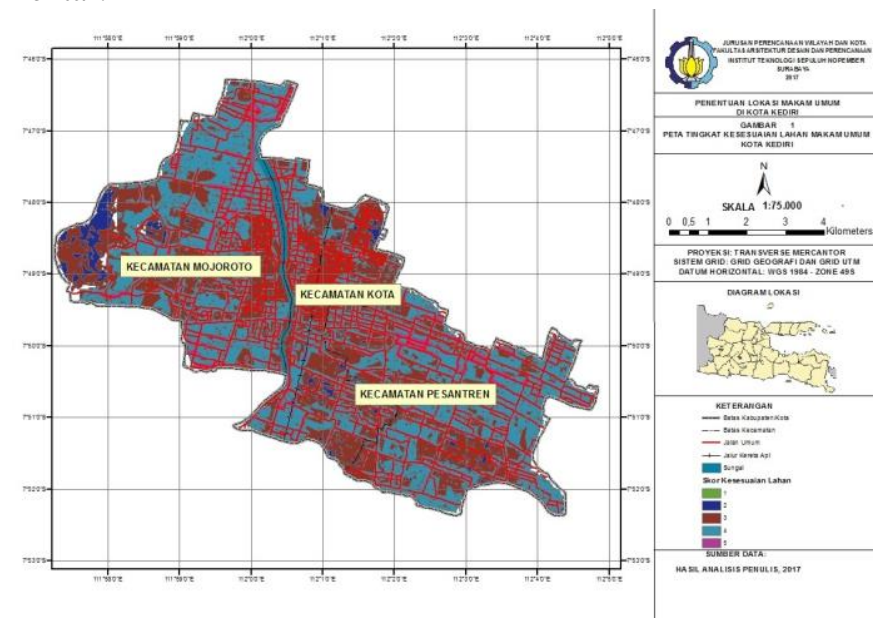

Gambar. 1. Peta Tingkat Kesesuaian Lahan Makam Umum Kota Kediri

\section{Menentukan Lokasi Fasilitas Makam Umum yang Ada di Kota Kediri}

Berdasarkan RTRW, diketahui ketiga lokasi alternatif berada di kawasan pariwisata. Semua alternatif lokasi berada di sekitar kawasan wisata Gunung Klotok. Berikut peraturan zonasi bagi wisata alam sebagaimana Perda nomor 1/2012. Penggunaan RTH (termasuk makam) dapat diizinkan meski terbatas (pasal 105). Yakni diutamakan untuk tekanan tinggi sebagaimana pada Ayat 2 huruf c.

Bisa disimpulkan bahwa makam baru merupakan perluasan dari Makam Klotok. Dari analisis ini dapat diketahui lokasi makam umum yang baru. Yakni di timur Gunung Klotok, dengan berbagai pertimbangan yang ada. Antara lain karakteristik ketiga lokasi beserta plus maupun minusnya. Berikut merupakan situasi kondisi dari masing-masing lokasi makam umum alternatif.
Tabel 7.

Karakteristik dari Masing-Masing Lokasi Makam Umum Alternatif di Kota Kediri

\begin{tabular}{|c|c|c|}
\hline No & $\begin{array}{l}\text { Letak Lokasi } \\
\text { Alternatif } \\
\text { Makam Umum } \\
\text { Baru Kota } \\
\text { Kediri } \\
\end{array}$ & Keterangan \\
\hline 1. & $\begin{array}{l}\text { Timur Area } \\
\text { Wisata Gunung } \\
\text { Klotok }\end{array}$ & $\begin{array}{l}\text { Merupakan alternatif lokasi yang paling luas } \\
\text { areanya daripada alternatif lainnya. Sehingga } \\
\text { paling dapat memenuhi kebutuhan makam } \\
\text { umum dibandingkan alternatif lainnya. Selain } \\
\text { itu, areanya cenderung berbentuk bulat, } \\
\text { sehingga memudahkan mobilitas pengunjung } \\
\text { makam. }\end{array}$ \\
\hline 2. & $\begin{array}{l}\text { Utara Area } \\
\text { Wisata Gunung } \\
\text { Klotok }\end{array}$ & $\begin{array}{l}\text { Luas areanya lebih sempit dibandingkan } \\
\text { alternatif lokasi pertama ( } 14,59 \text { ha). Selain itu, } \\
\text { bentuk areanya cenderung memanjang dari } \\
\text { utara ke selatan. Sehingga agak menyulitkan } \\
\text { pengunjung makam untuk berlalu-lalang } \\
\text { sepanjang area makam. }\end{array}$ \\
\hline 3. & $\begin{array}{l}\text { Sepanjang Jalan } \\
\text { Wisata Gunung } \\
\text { Klotok }\end{array}$ & $\begin{array}{l}\text { Luas areanya paling sempit dibandingkan } \\
\text { alternatif lokasi lainnya (12,31 ha). Selain itu, } \\
\text { bentuk areanya memanjang mengikuti jaringan } \\
\text { jalan yang ada. Sehingga berpotensi } \\
\text { mengganggu aktivitas jalan jaringan umum } \\
\text { yang telah ada. Apalagi jalan tersebut } \\
\text { merupakan jalan dalam area wisata Gunung } \\
\text { Klotok. }\end{array}$ \\
\hline
\end{tabular}

\section{KESIMPULAN/RINGKASAN}

Berikut merupakan kesimpulan yang diambil berdasarkan pembahasan dan analisis sebelumnya:

- Berdasarkan aspirasi masyarakat, berikut proporsi masingmasing indikator/variabel dalam kesesuaian lahan. Indikator penggunaan lahan, fisik, ekologi masing-masing 0,$398 ; 0,342$; dan 0,176 . Variabel nilai tanah dan pola jaringan jalan 0,428 dan 0,316 . Penggunaan lahan potensial dan Penggunaan lahan eksisting 0,160 dan 0,097. Topografi, kondisi kebencanaan, tingkat pergerakan tanah masing-masing 0,$418 ; 0,365 ; 0,217$. Sementara kawasan permukiman, hidrologi, dan geologi masing-masing 0,557 ; 0,$287 ; 0,156$.

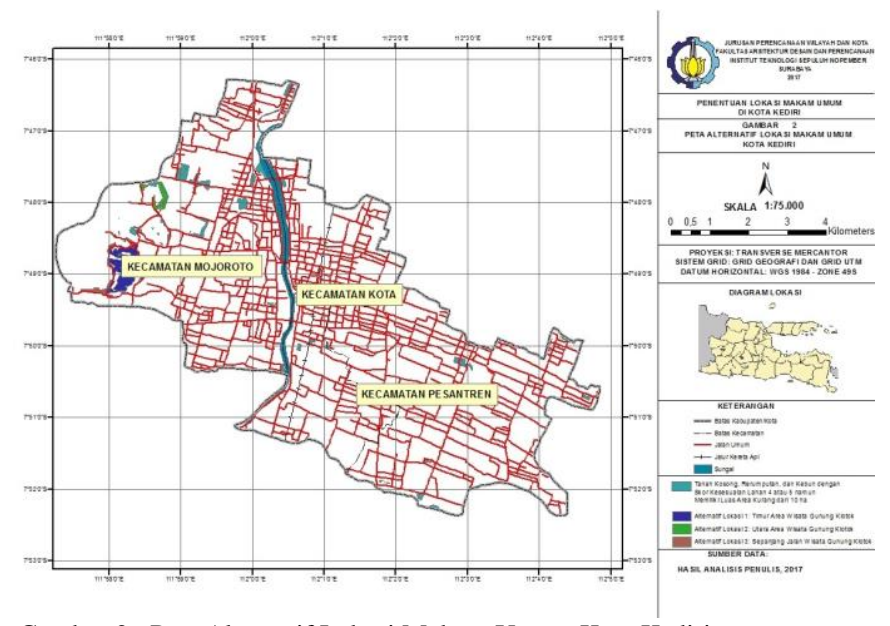

Gambar 2. Peta Alternatif Lokasi Makam Umum Kota Kediri. 
- Berikut merupakan perkiraan kebutuhan lahan makam umum di Kota Kediri. Yakni 0,45 ha setiap 5 tahun atau 0,09 ha pertahun.

- Dari hasil analisis GIS, diketahui tiga lokasi makam umum alternatif. Pertama yaitu timur Gunung Klotok, kedua yaitu utara Gunung Klotok. Adapun alternatif ketiga yaitu sepanjang jalan area wisata Gunung Klotok. Lokasi makam alternatif adalah lokasi dengan skor 4 dan 5. Penggunaannya lahan kosong, rerumputan, kebun, dengan luas minimal 10 ha.

- Berdasarkan kondisi eksisting disimpulkan mengenai lokasi makam umum yang baru. Yaitu alternatif lokasi yang berada di sebelah timur Gunung Klotok. Alasannya, lokasi tersebut paling luas areanya daripada alternatif lokasi lainnya. Selain itu kondisi areanya terlihat lebih menyatu daripada alternatif lainnya. Yang mana areanya lebih sempit dan banyak berhadapan dengan jalan.

\section{UCAPAN TERIMA KASIH}

Penulis M.S.A. mengucapkan terima kasih kepada dosen pembimbing, penguji, pihak instansi terkait, dan responden yang sangat membantu dalam penyelesaian artikel ini. Penulis juga diperkenankan menyampaikan ucapan terima kasih kepada keluarga dan teman-teman yang banyak memberikan dukungan dan doa.

\section{DAFTAR PUSTAKA}

[1] D. P. dan P. P. K. Kediri, Data Jumlah yang Dikubur pada Makam Umum Kota Kediri (hingga Oktober 2017). 2017.

[2] D. P. U. dan P. R. K. Kediri, Perencanaan Pengembangan Makam Umum Kota Kediri. kediri, 2015.

[3] P. Lieberman, Uniquely Human. Cambridge: Harvard University Press, 1991.

[4] S. Jonathan., Pilgrimage: An Image of Mediaeval Religion. London: Faber and Faber Ltd, 2002.

[5] A. S. A. P. W. Angga Sapto Aji, "Analisis Kesesuaian Kawasan Peruntukan Pemakaman Umum Baru Berbasis Sistem Informasi Geografis (SIG) (Studi Kasus: Kecamatan Tembalang, Kota Semarang)," Universitas Diponegoro, 2015.

[6] E. Neufert, Data Arsitek Edisi 3. Jakarta: Erlangga, 1991. 